\title{
New accountant job market reform by computer algorithm: an experimental study
}

\author{
Yoshitaka Hirose , $^{1 *}$ \\ ${ }^{1}$ Takasaki University of Commerce Junior College, Department of Business and Administration, 741 \\ Negoyamachi Takasaki Gunma, Japan
}

\begin{abstract}
The purpose of this study is to examine the matching of new accountants with accounting firms in Japan. A notable feature of the present study is that it brings a computer algorithm to the job-hiring task. Job recruitment activities for new accountants in Japan are one-time, shortterm struggles. Accordingly, many have searched for new rules to replace the current ones of the process. Job recruitment activities for new accountants in Japan change every year. This study proposes modifying these job recruitment activities by combining computer and human efforts. Furthermore, the study formulates the job recruitment activities by using a model and conducting experiments. As a result, the Deferred Acceptance (DA) algorithm derives a high truth-telling percentage, a stable matching percentage, and greater efficiency compared with the previous approach. This suggests the potential of the Deferred Acceptance algorithm as a replacement for current approaches. In terms of accurate percentage and stability, the DA algorithm is superior to the current methods and should be adopted.
\end{abstract}

\section{Introduction}

The purpose of this study is to present an improvement plan to address the problems of the labor market in Japan for Certified Public Accountants (CPA). Japan's successful CPA applicants do their job hunting simultaneously. Job hunting is a short-term, decisive battle. Consequently, accounting firms seek to obtain excellent, successful candidates [1]. The problem with this short-term, decisive battle has been noted previously. The problem has been identified in the United States labor market for medical doctors. However, the labor market of the United States for medical doctors has solved the problem using a computer algorithm. The labor market of Japanese medical doctors uses the same method. This study compares the labor market of these doctors and accountants and considers whether it is possible to use a computer algorithm in the labor market of the accountants.

The approach of this study is an analysis of game theory, which is referred to as matching theory [2]. The important point is the analysis of job hunting in game theory. Game theory can be used to discuss the design of institutions. The research method of this study is experimental research. Multiple alternatives may be compared in the experiment.

\footnotetext{
* Corresponding author: y-hirose@uv.tuc.ac.jp
} 
Carrying out the proposed analysis can result in pre-verification, with the aim of improving institutional design [3].

This paper is organized as follows. First, Section 2 reviews the previous studies and provides an overview of the labor market of the accountants. Next, Section 3 considers an effective algorithm for the solution of this problem. Section 4 then considers the experimental design. The results are shown in Section 5. Section 6 completes the discussion by showing the conclusions and noting future challenges.

\section{Previous studies and an overview of the labor market of the new accountants}

For new accountants, entering the labor market of Japan involves a short-term, decisive battle. Why has this become a short-term battle? To answer that question, it is necessary to understand the specific circumstances of Japan. First, consider the outline below.

Accounting jobs in Japan are the first jobs for many of the successful candidates. The majority of successful candidates are university students. The Japanese Institute of Certified Public Accountants (JICPA) oversees the new accountants in Japan's labor market. The JICPA conducts self-regulation to ensure that job hunting is carried out in a fair manner. The self-regulation of the JICPA is a fairly strong, compelling force for accounting firms. The JICPA has issued a notice every year for the accounting firms in Japan. The notice defines in detail the start dates for corporation briefings, interviewing, job offer notifications, and the like. Additionally, these rules change each year. The latest rules were published in 2015 [4]. This recent timeline is provided in Figure 1.

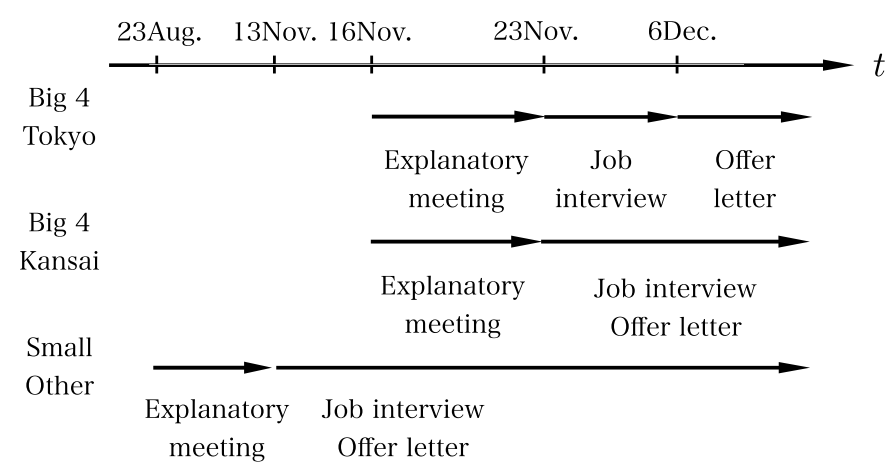

Fig. 1. Timeline of the current rules of job recruitment activities for new accountants.

To understand this figure, one must understand differences in regions and sizes.

The JICPA is divided into three accounting firm groups: (1) Tokyo district of major accounting firms, (2) Kansai district of major accounting firms, and (3) other regions with major accounting firms and small and medium-sized accounting firms. Here, the major accounting firms are the Big 4. More specifically, the Big 4 consists of Ernst \& Young, Deloitte, KPMG, and PricewaterhouseCoopers. The Kansai region includes Osaka, Kyoto, and Kobe.

Accounting firms have been requested to comply with the rules of the JICPA. Accordingly, recruitment activities proceed along the schedule of Fig 1. This figure indicates that the recruitment activities of small and medium-sized accounting firms begin first. For accounting firms of small and medium size, it is possible to hold an explanatory meeting immediately after the end of the CPA exam. Accounting firms of small and 
medium size can also start the job interview process immediately after the CPA exam results are announced, and they can begin sending offer letters. Then the recruiting activities of Kansai and Tokyo's major accounting firms begin. Specifically, Kansai and Tokyo's major accounting firms can hold explanatory meetings beginning on November 16. They can start job interviews on November 23. A major accounting firm in the Kansai region is able to begin sending offer letters on November 23. However, major accounting firms in Tokyo start sending offer letters after December 3. According to the JICPA, accounting firms will not be able to make an offer to a specific person before the "offer letter start." The further details of this rule are as follows:

Type 1. For the major audit firms' Tokyo offices, explanatory meetings start November 16 (Monday) (application acceptance starts November 13 (Friday) 12:00), job interviews start November 23 (Monday) 9:00 (application acceptance starts November 19 (Thursday) 15:00), and offer letters begin after December 3 (Thursday) 9:00 (the joining acceptance period is December 5 (Saturday) 12:00).

Type 2. For the major audit firms' Kansai district offices, explanatory meetings start November 16 (Monday) morning (application acceptance starts November 13 (Friday) 12:00), job interviews start November 23 (Monday) 9:00 (application acceptance starts November 19 (Thursday) 15:00), and offer letters begin any time from the start of the interviews (the joining acceptance period is November 27 (Friday) 17:00).

Type 3. For firms that are not Kansai or Tokyo major accounting firms, including small and medium-sized accounting firms, explanatory meetings can be conducted any time after the end of the CPA exam. However, acceptance of the job interview is carried out after the exam results are announced. The explanatory meeting and offer letter start are determined via consultation in each region.

In this way, the accounting firms may be subject to any of three rules. The application of the rules differs according to firm size and region. A notable aspect of this rule is that the joining acceptance period is established in the Kansai and Tokyo's major accounting firms. Additionally, the joining acceptance deadline has been designated by both date and time. After the joining acceptance deadline of the major accounting firms in the Kansai region passes, the starting date for offer letters of Tokyo's major accounting firms begins. Accordingly, a person who has accepted a job offer form a major accounting firm in the Kansai region cannot possibly consider joining a major accounting firm in Tokyo. Therefore, job hunting for new accountants has become something like a bet. The most typical case is for an accountant to accept a job in Kansai despite wanting to work in Tokyo. Others accept jobs in small and medium-sized firms even though they want to work in Tokyo or Kansai. In other words, Tokyo and Kansai's major accounting firms have missed the opportunity to acquire top talent. The current rules for new accountants and accounting firms are inefficient. However, the accounting firms that are small or mediumsized and those offices of the Big 4 that are not in Tokyo or Kansai might gain excellent employees that could not be obtained without the current rules. In this way, the interests of the audit firms have conflicted. The JICPA has proceeded by trial and error. However, the employment recruitment of new accountants and audit firms remains, basically, an irreversible "one-shot deal."

\section{Model: Computational algorithm}

Consider the real world to be of the essence, as discussed in the previous section. An offer letter that an audit firm sends out is an exploding offer. It must be answered immediately. The new accountant must choose to accept or reject by the deadline.

In this section, we consider a job recruitment activity that combines computers and humans. First, I consider a valid computer algorithm to solve this problem. Other 
professionals in the labor market, according to previous studies, are subject to a residency (training physician) matching. The matching of training physicians with hospitals is being analyzed in the field. Such research has been applied to the real world [2].

Previous research identifies three criteria for determining the desirability of matching [2]. They are: (1) truth telling, (2) stability, and (3) efficiency.

1. Truth telling: The truth telling criteria is the requirement that job searchers make honest decisions regarding their preferences. Often, people lie to themselves in the process of job hunting. It is better, however, to job hunt honestly without lying to oneself.

2. Stability: The stability criteria is that everyone in the state that does not have an incentive to the ran missing. Conversely, matching parties that do not have a mutual affection results in employment situations that are not stable.

3. Efficiency: The efficiency criteria are that of Pareto efficiency in welfare economics.

One algorithm that satisfies the truth telling and stability criteria is the Deferred Acceptance (DA) algorithm [5]. This algorithm has been applied to the real world in training physicians matching and school matching. The DA algorithm is as follows.

Step 1: Each new accountant applies for his/her first choice of accounting firms. Each accounting firm accepts new accountants until its capacity is filled. Each accounting firm declines the rest of the new accountants.

Step k: New accountants that were refused in the k-1 step apply for their first choices in the accounting firms that are not otherwise specified. Each accounting firm compares the new entrants and keeps the new accountant. Each accounting firm declines the rest of the new accountants.

End: The algorithm is terminated when the new accountants who were refused are gone. Each accounting firm will have formally adopted new accountants that it will keep.

Actually, though, new accountants do not apply, and accounting firms do not decide to keep them. Essentially, a centralized third party makes the matching determination using a computer. Specifically, JICPA and the Financial Services Agency could cooperate to accomplish this. This is realistic because there is precedent in the cooperation of the Medical Association and the Ministry of Health, Labour and Welfare with a third party organization.

\section{Experimental Design}

The experimental design was based on previous research referenced $[2,6]$. The experiment targeted Doshisha University undergraduates in July 2013 and January 2014. A total of 131 people participated in the following two treatments. The CR (current rule) involved 35 people and the DA (Deferred Acceptance) involved 96 people a subset of 33 people was examined.

The subjects played the role of new accountants' job hunting with three accounting firms, in three-person sets. The hiring capacity of the three accounting firms is one person each. The subjects participate in the experiment for only one of the two conditions (i.e., CR or DA). I conducted a between-subjects design experiment. The experimental procedure consisted of the following steps: First, the experimenter explained the instructions. The experimenter answered any questions. Then the experimenter distributed a document stating the true preference ranking of each subject. The true preference ranking that was distributed to each of the subjects constituted private information. The subjects could not know the true preference order of other subjects. Subjects of the CR treatment were either selected or not selected for entry into each of the accounting firms. For subjects of the DA treatment, three rankings of the accounting firms were selected. Each condition was subject to decision only once. Subjects did not perform repetitive decisions. In addition to having gained the psychological data, the experimenter performed a post-questionnaire of 
behavioral data for both conditions. Incidentally, the preference order of the accounting firms and the conditions were fixed. In addition, the decision-making of each audit firm was performed by a computer. Each accounting firm of the CR treatment selected higher preference order new accountants. Additionally, each accounting firm of the DA treatment expressed the true preference ranking. Such accounting firms submitted their data without faking the ranking of their desire for new accountants. The true preference rankings of these accounting firms was information that was not known to all subjects. Subjects won three points when they were assigned to the first position of an audit firm. Subjects won two points when they were assigned to the second position of an audit firm. Subjects won one point when they were assigned to the third position of an audit firm. The mean duration of the experiment was about 30 minutes. It should be noted that experiments were carried out context-free. I set the following parameters in the experiment.

Table 1. True preference ranking of the new accountants.

\begin{tabular}{|c|c|c|c|}
\hline & New accountant 1 & New accountant 2 & New accountant 3 \\
\hline First rank & Type 2 & Type 1 & Type 1 \\
\hline Second rank & Type 1 & Type 2 & Type 2 \\
\hline Third rank & Type 3 & Type 3 & Type 3 \\
\hline
\end{tabular}

Table 2. True preference ranking of the accounting firms.

\begin{tabular}{|c|c|c|c|}
\hline & Accounting firm 1 & Accounting firm 2 & Accounting firm 3 \\
\hline First rank & New accountant 1 & New accountant 2 & New accountant 2 \\
\hline Second rank & New accountant 3 & New accountant 1 & New accountant 1 \\
\hline Third rank & New accountant 2 & New accountant 3 & New accountant 3 \\
\hline
\end{tabular}

\section{Results}

This section shows the experimental results. Three of the results indicate the desirability of the criteria for matching are "truth telling, stability, and efficiency.

Result 1. The DA treatment has a higher truth-telling percentage than the CR treatment.

Statistical evidence. I conducted a Welch Two Sample t-test for the difference between the mean values of the two treatments. Under each mechanism, the null hypothesis of equal proportions of truth-telling revelation across the two treatment settings can be rejected at the $1 \%$ significance level. $\mathrm{t}=-3.125, \mathrm{df}=63.959, \mathrm{p}$-value $=0.003$. The mean of truth telling is listed in the following table.

Result 2. The DA treatment has a higher stable matching percentage than the $C R$ treatment.

Statistical evidence. I conducted a Welch Two Sample t-test for the difference between the mean values of the two treatments. Under each mechanism, the null hypothesis of equal proportions of stable matching revelation across the two treatment settings can be rejected at the $1 \%$ significance level. $\mathrm{t}=-3.796, \mathrm{df}=17.101, \mathrm{p}$-value $=0.001$. The mean of stable matching outcomes is listed in the following table.

Result 3. The DA treatment has higher efficiency than the CR treatment.

Statistical evidence. I conducted a Welch Two Sample t-test for the difference between the mean values of the two treatments. Under each mechanism, the null hypothesis of equal proportions of efficiency across the two treatment settings can be rejected at the $5 \%$ significance level. $\mathrm{t}=-2.725, \mathrm{df}=12.079$, $\mathrm{p}$-value $=0.018$. The mean of efficiency is listed in the following table. 
Table 3. The proportion of truth telling, stability, and efficiency.

\begin{tabular}{|c|c|c|}
\hline & CR & DA \\
\hline Truth telling & $30.3 \%$ & $66.7 \%$ \\
\hline Stability & $9.0 \%$ & $72.7 \%$ \\
\hline Efficiency & $72.7 \%$ & $87.0 \%$ \\
\hline
\end{tabular}

Therefore, the DA treatment was found to exhibit higher truth telling, stability, and efficiency than the CR treatment.

\section{Conclusion}

In this paper, I compare the current rules and the DA algorithm. The main results of this study are as follows: 1) The DA treatment has a higher truth-telling percentage than the CR treatment. The way in which current rules tend to apply for a small accounting firm was observed. 2) The DA treatment has a higher stable matching percentage than the CR treatment. 3) The DA treatment has higher efficiency than the CR treatment.

These results lead to the following suggestions. Under the current rules for new accountants, people who engage in job hunting do not pursue their true preference. Stable matching is low under the current rules. The Deferred acceptance alternative to the current rules can solve these problems. It will ensure that new accountants are able to express their true preference rankings. Moreover, it will result in stable matching. This is a good thing for both new accountants and accounting firms. Efficiency is a measure that has been considered desirable in traditional accounting and economics. However, truth telling and stability are measures that are used in market design, matching theory, and game theory. Accordingly, humans need to take advantage of the power of the computer algorithm.

\section{References}

1. Japan Auditing Association, Certified Public Accountants examination system (Daiichihoki, 1993)

2. A. E. Roth, International Journal of Game Theory, 36, 3-4 (2008)

3. S. Taguchi, An experimental Institutional Accounting: A future design for accounting, (Chuo-Keizai-Sha, 2015)

4. Japanese Institute of Certified Public Accountants, The start time of the recruitment activities of the current fiscal year of the Certified Public Accountant exams, (2015)

5. D. Gale, L. S. Shapley, The American Mathematical Monthly, 69, 1 (1962)

6. J. Pais, Á. Pintér, Games and Economic Behavior, 64.1 (2008) 